\title{
LncRNA PCGEM1 Induces Ovarian Carcinoma Tumorigenesis and Progression Through RhoA Pathway
}

\author{
Shuo Chen ${ }^{\mathrm{a}}$ Li-li Wang ${ }^{\mathrm{b}} \quad$ Kai-xuan Sun ${ }^{\mathrm{b}} \quad$ Yao Liu ${ }^{\mathrm{b}} \quad$ Xue Guan ${ }^{\mathrm{b}} \quad$ Zhi-hong Zong ${ }^{\mathrm{a}, \mathrm{c}}$ \\ Yang Zhao
}

aDepartment of Obstetrics and Gynecology, The Third Affiliated Hospital of Guangzhou Medical University, Key laboratory for Major Obstetric Diseases of Guangdong Province, and Key Laboratory of Reproduction and Genetics of Guangdong Higher Education Institute in Guangdong Province, Guangzhou, bepartment of Gynecology, the First Affiliated Hospital of China Medical University, Shenyang, 'Department of Biochemistry and Molecular Biology, College of Basic Medicine, China Medical University, Shenyang, P. R. China.

\section{Key Words}

Lncrna PCGEM1 • RhoA • Ovarian cancer • Tumorigenesis and progression

\begin{abstract}
Background/Aims: Prostate cancer gene expression marker 1 (PCGEM1) is a long noncoding RNA (IncRNA) and is well known as a promoter in prostate cancer and osteoarthritis synoviocytes. However, the role PCGEM1 plays in epithelial ovarian cancer is unknown. Methods: PCGEM1 expression was examined in epithelial ovarian cancer and normal ovarian tissues using reverse transcription-PCR. Ovarian cancer cell phenotypes and genotypes were examined after PCGEM1 overexpression or downregulation in vitro; besides, the effects of PCGEM1 overexpression was also examined in vivo. Results: PCGEM1 expression level was higher in epithelial ovarian cancer tissues than in normal ovarian tissues and was positively associated with differentiation (Well vs. Mod/Poor). Upregulation of PCGEM1 induced cancer cell proliferation, migration, and invasion, but decreased cell apoptosis through upregulating RhoA, YAP (Yes-associated protein), MMP2 (matrix metalloproteinase 2), Bcl-xL, and P70S6K expression; while PCGEM1 downregulation had the opposite effect. The nude mouse xenograft assay demonstrated that PCGEMI overexpression promoted tumor growth. Furthermore, silencing RhoA expression reversed the effect of PCGEM1 and significantly inhibited RhoA, YAP, MMP2, Bcl-xL, and P70S6K protein expression. Conclusion: In conclusion, we suggest that PCGEM1 may be an inducer in epithelial ovarian cancer tumorigenesis and progression by upregulating RhoA and the subsequent expression of YAP, P70S6K, MMP2, and Bcl-xL.




\section{Introduction}

As the development of ovarian cancer is asymptomatic, it is usually diagnosed at a late stage, and remains the most lethal gynecological malignancy [1], with the 5-year survival rate less than $30 \%$ [2]. Despite existing research series, there are few reliable biomarkers for early detection, and the related molecular mechanisms contributing to ovarian cancer tumorigenesis and progression require further exploration.

Long noncoding RNAs (lncRNAs, >200-nucleotide length) influence multiple biological processes, including proliferation, apoptosis, senescence, and differentiation in various diseases, especially in cancer [3], and are regarded as an emerging alternative target for cancer therapy.

Prostate cancer gene expression marker 1 (PCGEM1) is an lncRNA that was initially found to be overexpressed in aggressive prostate cancers; a series of studies has shown that PCGEM1 is closely related to prostate cancer cell proliferation [4]. Moreover, exogenous overexpression of PCGEM1 inhibits cell apoptosis, induces cell autophagy, and stimulates the cell proliferation of human synoviocytes [5], suggesting that it may play an oncogenic role in tumorigenesis and cancer progression and may have potential to be a therapeutic target in cancer. However, its function in ovarian cancer is unknown.

Previously, we found that RHOA knockdown reduced ovarian cancer cell proliferation, promoted apoptosis, suppressed lamellipodia formation, cell migration and invasion by downregulating the relevant genes [6]. A number of lncRNAs have been identified as competing endogenous RNAs (ceRNAs) that reduce the activity of the target microRNAs without essentially altering their biogenesis [7-10]. Using bioinformatic predictions, we found a direct interaction between PCGEM1 and miR-129-5p, and between RhoA and miR-129-5p. Therefore, we suggest that, overall, PCGEM1 may promote ovarian cancer tumorigenesis and progression by targeting RhoA and modulating the RhoA downstream factors. Accordingly, we investigated the role of PCGEM1 in the pathogenesis and progression of ovarian cancer and the potential molecular mechanism involved.

\section{Materials and Methods}

\section{Ovarian cancer specimens}

We collected 14 normal ovarian tissue and 50 epithelial ovarian cancer tissue specimens from patients who had undergone surgical resection at the Department of Gynecology of the First Affiliated Hospital of China Medical University (Shenyang, China). Two pathologists confirmed the tumor specimens independently. The specimens were frozen immediately in liquid nitrogen and stored at $-80^{\circ} \mathrm{C}$ until used. The China Medical University Ethics Committee approved the study, and all specimens were handled and anonymized according to ethical and legal standards (No: 2014-27); informed consent was obtained from all subjects.

\section{Cell culture and transfection}

Thehumanovarian cancer celllines A2780 and OVCAR3 were purchasedfromJennio Biotech(Guangdong, China). A2780 cells were cultured in Dulbecco's modified Eagle's medium (HyClone, Logan, UT, USA); the OVCAR3 cells were cultured in RPMI 1640 medium (HyClone). Both culture mediums were supplemented with penicillin/streptomycin $(100 \mathrm{U} / \mathrm{mL})$ and $10 \%$ fetal bovine serum (FBS). The cells were cultured at $37^{\circ} \mathrm{C}$ and $5 \% \mathrm{CO}_{2}$ atmosphere in an incubator. All transfection experiments were carried out according to the manufacturer's instructions using Lipofectamine 2000 (Invitrogen, Carlsbad, CA, USA). The PCGEM1 short interfering RNA (siRNA) sense and anti-sense sequences were 5'-GGAAACAACCUUUAACUUAdTdT-3' and $5^{\prime}$-UAAGUUAAAGGUUGUUUCCdTdT-3', respectively. The sense and anti-sense target sequences of RhoA siRNA were 5'-GUUUAUUAAUCUUAGUGUAdTdT-3' and 5'-UACACUAAGAUUAAUAAACdTdT-3', respectively.

Tetrazolium (MTT) assay

To examine cell viability, 3000 cells per well were seeded in 96-well plates. At $0 \mathrm{~h}, 24 \mathrm{~h}, 48 \mathrm{~h}$, and $72 \mathrm{~h}$ after seeding, the cells were incubated with $20 \mu \mathrm{L} 5 \mathrm{mg} / \mathrm{mL}$ MTT solution (Solarbio, Beijing, China) 


\section{Cellular Physiology Cell Physiol Biochem 2018;47:1578-1588 \begin{tabular}{l|l} 
and Biochemistry Published online: June 27, 2018 & $\begin{array}{l}\text { C } 2018 \text { The Author(s). Published by S. Karger AG, Basel } \\
\text { www.karger.com/cpb }\end{array}$ \\
\hline
\end{tabular}}

Chen et al.: The Role of PCGEM1 in Ovarian Carcinoma

at $37^{\circ} \mathrm{C}$ for $4 \mathrm{~h}$. Then, the solution was removed, and the precipitated formazan was dissolved in $150 \mu \mathrm{L}$ dimethyl sulfoxide. After shaking for $10 \mathrm{~min}$, the absorbance at $570 \mathrm{~nm}$ was determined using a microplate spectrophotometer (BioTek Instruments, Winooski, VT, USA).

\section{Apoptosis assay}

Cells were collected and washed twice with cold phosphate-buffered saline (PBS). For PCGEM1 plasmid transfection, apoptosis was quantified with flow cytometry using 7-amino-actinomycin and phycoerythrinlabeled annexin V (BD Biosciences, San Jose, CA, USA) according to the manufacturer's protocol. For siRNA transfection, apoptosis was quantified with flow cytometry using annexin V-fluorescein isothiocyanate and propidium iodide (BD Biosciences). The apoptosis rate was determined by flow cytometry within $1 \mathrm{~h}$ of staining.

\section{Wound healing assay}

Cells were cultured to $80 \%$ confluence in 6-well culture plates, after which the monolayers were scratched with a 200- $\mu \mathrm{L}$ pipette tip. The cells were washed with PBS and cultured in FBS-free medium containing mitomycin $\mathrm{C}(20 \mu \mathrm{g} / \mathrm{mL})$. The wounds were observed and photographed under a light microscope at $0 \mathrm{~h}, 24 \mathrm{~h}$, and $48 \mathrm{~h}$. ImageJ software (National Institutes of Health, Bethesda, MD, USA) was used to measure the wound areas. The wound healing rate was determined as follows: (area of original wound - area of wound at different times)/area of original wound $\times 100 \%$.

\section{Invasion assay}

Matrigel-coated Transwell cell culture chambers were used for the invasion assay. Filters were coated with $30 \mu \mathrm{L}$ cold basement membrane Matrigel (1:15, BD Biosciences) and allowed to set for $4 \mathrm{~h}$ in an incubator. Cells $\left(5 \times 10^{4} / \mathrm{L}\right)$ were resuspended in $200 \mu \mathrm{L}$ serum-free medium and layered in the top compartment of the Transwell inserts. The bottom chambers contained $600 \mu \mathrm{L}$ medium containing $10 \%$ FBS, which served as the chemoattractant. After 48-h incubation, cells on the upper surface of the filter were removed. The cells that had invaded to the bottom of the top chamber were fixed with formaldehyde, stained with crystal violet, and counted.

\section{Quantitative reverse transcription-PCR ( $q R T-P C R)$}

Total RNA was isolated from ovarian carcinoma cell lines and tissues with TRIzol (Takara, Shiga, Japan) and measured with a spectrophotometer (Unico, Shanghai, China). Then, $2 \mu \mathrm{g}$ RNA was reverse-transcribed to complementary DNA (cDNA) using avian myeloblastosis virus transcriptase and random primers according to the manufacturer's protocol (Takara). Then, the cDNA was amplified by real-time qPCR using a SYBR Premix Ex Taq II kit (Takara). The relative expression of the target genes was determined by comparing the threshold cycle (Ct) of the target genes to that of $18 \mathrm{~S}$ rRNA using the $2^{-\Delta \Delta \mathrm{Ct}}$ method (GenePharma).

\section{Western blotting}

The complete ovarian cancer cell proteome was extracted in radioimmunoprecipitation assay buffer, which prevented protease-mediated sample degradation. The protein concentration for each sample was determined, after which $40 \mu$ g protein was resolved by $10 \%$ or $15 \%$ sodium dodecyl sulfate-polyacrylamide gel electrophoresis, followed by electrotransfer to Hybond membranes (Amersham, Munich, Germany). After blocking with 5\% fat-free milk at room temperature for $2 \mathrm{~h}$, the membranes were incubated with primary antibodies against RhoA, P70S6K, MMP2, YAP, and Bcl-xL (1:1000; Proteintech, Rosemont, IL, USA) at $4^{\circ} \mathrm{C}$ overnight. The membranes were washed with Tris-buffered saline containing Tween-20 (TBST) three times, and then anti-rabbit secondary antibody (1:5000) was added. After 1-h incubation at room temperature, the protein bands were visualized by enhanced chemiluminescence according to the manufacturer's instructions (Santa Cruz Biotechnology, Santa Cruz, CA, USA). $\beta$-actin (1:3000; Proteintech) was served as the internal control.

\section{In vivo tumorigenesis model}

An in vivo model of ovarian cancer was established by subcutaneously injecting 4-week-old female BALB/c nude mice with $1 \times 10^{7}$ lncRNA PCGEM1 (or mock)-transfected A2780 cells suspended in PBS (eight mice per group). The weight of the mice and tumor volumes were measured every 3 days. Tumor volume 


\section{Cellular Physiology Cell Physiol Biochem 2018;47:1578-1588 \begin{tabular}{l|l} 
and Biochemistry Published online: June 27, 2018 & $\begin{array}{l}\text { (c) 2018 The Author(s). Published by S. Karger AG, Basel } \\
\text { www.karger.com/cpb }\end{array}$ \\
\hline
\end{tabular} \\ Chen et al.: The Role of PCGEM1 in Ovarian Carcinoma}

was assessed by measuring the tumor length (L) and width (W) with calipers (tumor volume $\left[\mathrm{mm}^{3}\right]=0.5 \times \mathrm{L}$ $\times \mathrm{W}^{2}$ ). After 4 weeks, the mice were euthanized and the tumors were excised, measured, and photographed. All mice were obtained from Vital River Laboratories (Beijing, China) and housed in a specific pathogen-free environment. The experiment was conducted in accordance with the National Institutes of Health Guide for the Care and Use of Laboratory Animals and was approved by the China Medical University Animal Care and Use Committee.

\section{Immunohistochemistry}

Consecutive tissue sections were deparaffinized with xylene, rehydrated with alcohol, and subjected to antigen retrieval by heating in target retrieval solution (Dako) for $15 \mathrm{~min}$ in a microwave oven (Oriental Rotor). The sections were quenched with 3\% hydrogen peroxide for 20 min to block endogenous peroxidase activity. Nonspecific binding was prevented by adding $5 \%$ bovine serum albumin for 5 min. The sections were incubated with the RhoA antibody $(1: 100)$ at $4^{\circ} \mathrm{C}$ overnight and then incubated with horseradish peroxidase-conjugated anti-rabbit antibody (Dako) for $30 \mathrm{~min}$ at $37^{\circ} \mathrm{C}$. After each treatment, the slides were washed three times with TBST for $5 \mathrm{~min}$ and were visualized with 3, 3'-diaminobenzidine. After counterstaining with Mayer's hematoxylin, the sections were dehydrated, cleared, and mounted. Negative controls were prepared by omitting the primary antibody.

\section{Statistical analysis}

Data are reported as the mean \pm SD and were analyzed using SPSS 18.0 software (SPSS Inc., Chicago, IL, USA). The unpaired two-tailed Student $t$-test, MannWhitney U-test, and Spearman correlation test were used to compare the two groups. All $P$-values are two-sided; $P<$ 0.05 indicates statistical significance.

\section{Results}

Correlation of IncRNA PCGEM1 expression with epithelial ovarian carcinoma tumorigenesis and progression

LncRNA PCGEM1 expression was quantified in ovarian cancer tissues and normal ovarian tissues using qRT-PCR. We found that LncRNA PCGEM1 expression was significantly higher in ovarian cancer tissues than in normal ovarian tissues (Fig. 1A, Table1, $P<0.05$ ). In the ovarian cancer tissues, LncRNA PCGEM1 expression was positively associated with differentiation (well vs. mod/poor, Fig. 1B, Table2, $P<0.05$ ).

Effect of PCGEM1 overexpression on ovarian cancer cell proliferation, apoptosis, and aggressiveness in vitro

LncRNA PCGEM1 was highly expressed in the A2780 and OVCAR3 cells after PCGEM1 transfection (Fig. 2A, $P<$ 0.05). PCGEM1 overexpression induced significant cell proliferation (Fig. $2 \mathrm{~B}, P<0.05)$, decreased apoptosis (Fig. 2C, $P<0.05$ ), and increased cell migration (Fig. 2D, $P<0.05$ ) and invasion ability (Fig. $2 \mathrm{E}, P<$ $0.05)$ as compared to the vector group.

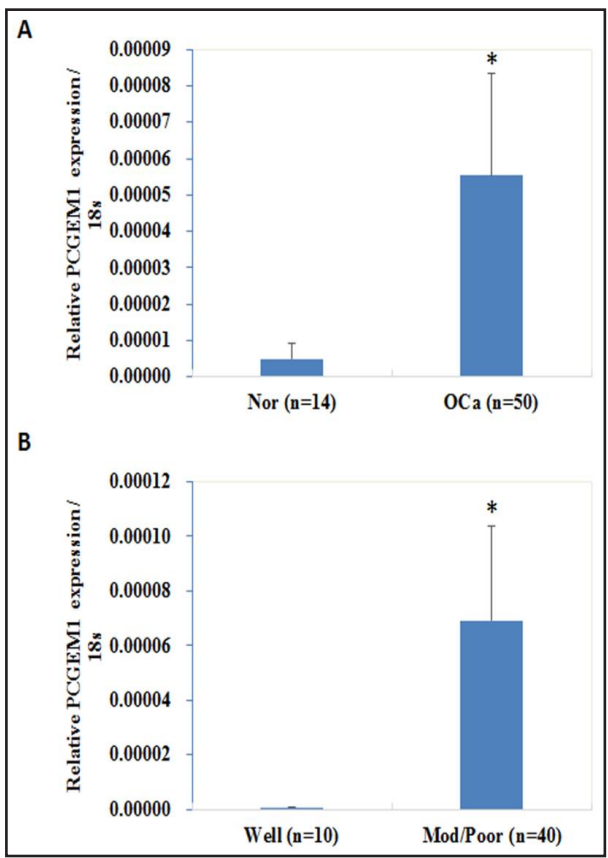

Fig. 1. Correlation of PCGEM1 expression with epithelial ovarian carcinoma tumorigenesis and progression. (A) PCGEM1 expression was higher in ovarian cancer tissues than in normal ovarian tissues. (B) PCGEM1 expression was higher in Mod/ Poor differentiation group than in Well Differentiation group. ${ }^{*} \mathrm{P}<0.05$.

Table 1. PCGEM1 expression in normal ovary and ovarian carcinoma tissues. Bold and Italics means $\mathrm{P}<0.05$

\begin{tabular}{llcc}
\hline Groups & N & PCGEM1 expression / 18s & P value \\
\hline Normal ovary & 14 & $4.929 \mathrm{E}-06 \pm 1.649 \mathrm{E}-05$ & $\mathbf{0 . 0 4 1}$ \\
Ovarian carcinoma & 50 & $5.538 \mathrm{E}-05 \pm 0.0001981$ & \\
\hline
\end{tabular}


Table 2. Correlation of PCGEM1 expression with different clinicopathological features of ovarian carcinoma. Bold and Italics means $\mathrm{P}<0.05$

\begin{tabular}{|c|c|c|c|}
\hline Clinicopathological features & $\mathrm{N}$ & PCGEM1 expression / 18s & $P$ value \\
\hline The pathology types & & & 0.315 \\
\hline Serous carcinoma & 42 & $4.952 \mathrm{E}-05 \pm 0.0002015$ & \\
\hline The other pathology types & 8 & $8.610 \mathrm{E}-05 \pm 0.0001887$ & \\
\hline Age & & & 0.076 \\
\hline$\leq 52$ & 26 & $1.462 \mathrm{E}-05 \pm 4.859 \mathrm{E}-05$ & \\
\hline$>52$ & 24 & $9.953 \mathrm{E}-05 \pm 0.0002777$ & \\
\hline FIGO stages & & & 0.371 \\
\hline I-II & 16 & $4.286 \mathrm{E}-05 \pm 0.0001361$ & \\
\hline III-IV & 34 & $6.080 \mathrm{E}-05 \pm 0.0002231$ & \\
\hline Pathology classification & & & 0.028 \\
\hline Well & 10 & $5.657 \mathrm{E}-07 \pm 8.063 \mathrm{E}-07$ & \\
\hline Mod + Poor & 40 & $6.908 \mathrm{E}-05 \pm 0.0002199$ & \\
\hline
\end{tabular}

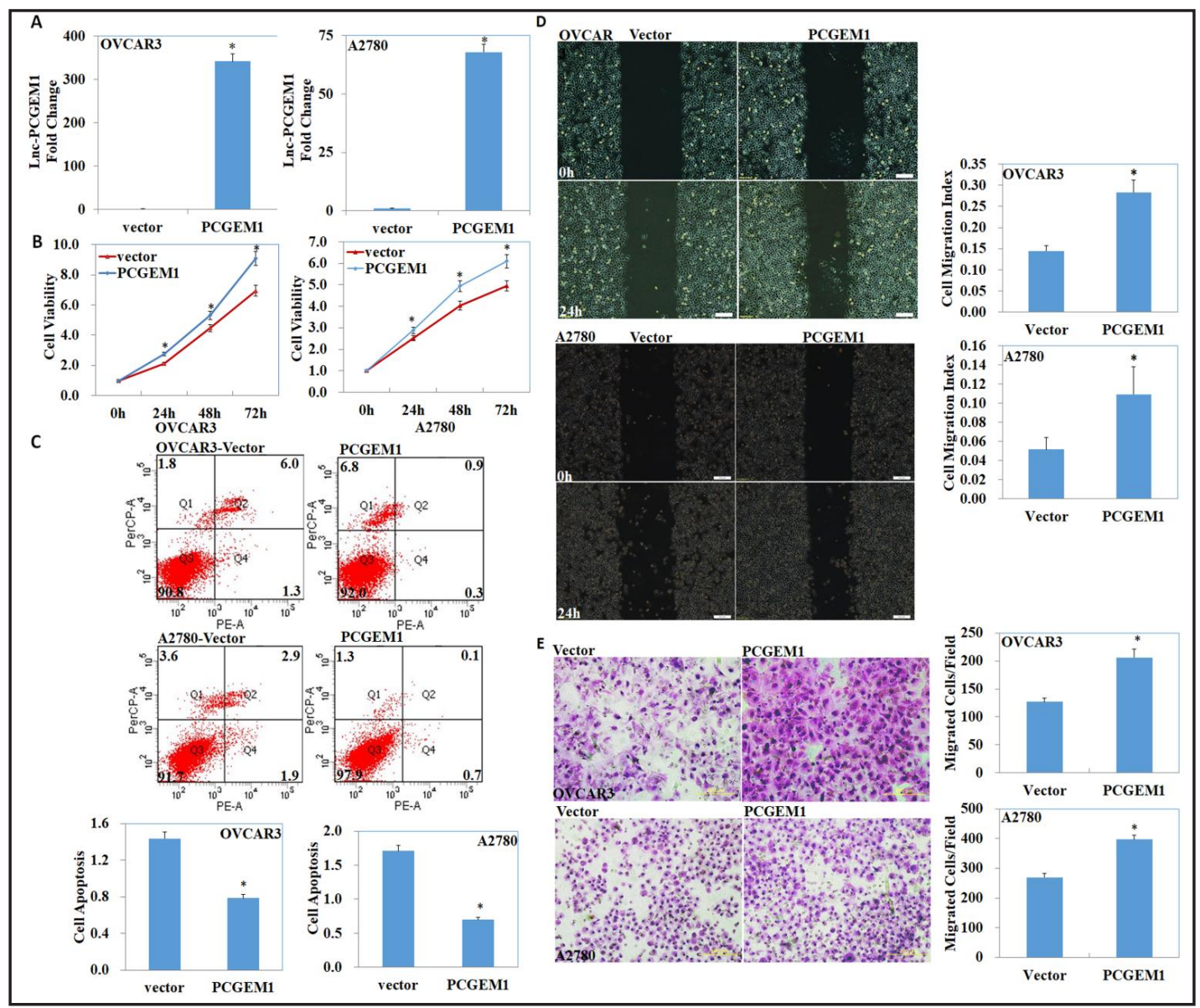

Fig. 2. Effect of PCGEM1 overexpression on ovarian cancer cell proliferation, apoptosis, and aggressiveness in vitro. (A) PCGEM1 overexpression induced (B) cell proliferation, (C) decreased apoptosis, and increased (D) cell migration and (E) invasion ability. Results are representative of three separate experiments; data are the mean $\pm \mathrm{SD} . * \mathrm{P}<0.05$. 


\section{Cellular Physiology Cell Physiol Biochem 2018;47:1578-1588 \begin{tabular}{l|l} 
DOI: 10.1159/000490931 & and Biochemistry \\
Published online: June 27, 2018 & $\begin{array}{l}\text { 2018 The Author(s). Published by S. Karger AG, Basel } \\
\text { www.karger.com/cpb }\end{array}$
\end{tabular} \\ Chen et al.: The Role of PCGEM1 in Ovarian Carcinoma}

Effect of PCGEM1 downregulation on ovarian cancer cell proliferation, apoptosis, and aggressiveness in vitro

LncRNA PCGEM1 was downregulated in the A2780 and OVCAR3 cells after PCGEM1 siRNA transfection (Fig. 3A, $P<0.05$ ). PCGEM1 downregulation reduced cell proliferation (Fig. 3B, $P<0.05$ ), increased cell apoptosis (Fig. 3C, $P<0.05$ ), and decreased cell migration (Fig. 3D, $P<0.05$ ) and invasion ability (Fig. $3 \mathrm{E}, P<0.05$ ) as compared to the si-Scramble group.

\section{Effect of PCGEM1 transfection on ovarian carcinoma cell genotype in vitro}

Western blotting results demonstrated that PCGEM1 overexpression upregulated RhoA, YAP, P70S6K, MMP2, and BCL-xL protein expression (Fig. 4A), while PCGEM1 downregulation downregulated RhoA, YAP, P70S6K, MMP2, and BCL-xL protein expression (Fig. 4B).

\section{Effect of PCGEM1 on tumor growth in vivo}

BALB/c nude mice were subcutaneously injected with $1 \times 10^{7}$ lncRNA PCGEM1 or mocktransfected A2780 cells (8 mice per group), the tumor xenograft volume in the PCGEM1transfected nude mice was significantly greater than that in the control mock-transfected mice (Fig. 5A-B \& D, $P<0.05$ ), and the tumor growth rate was also significantly greater in the PCGEM1-transfected mice (Fig. 5C, $P<0.05$ ). Immunohistochemical analysis demonstrated

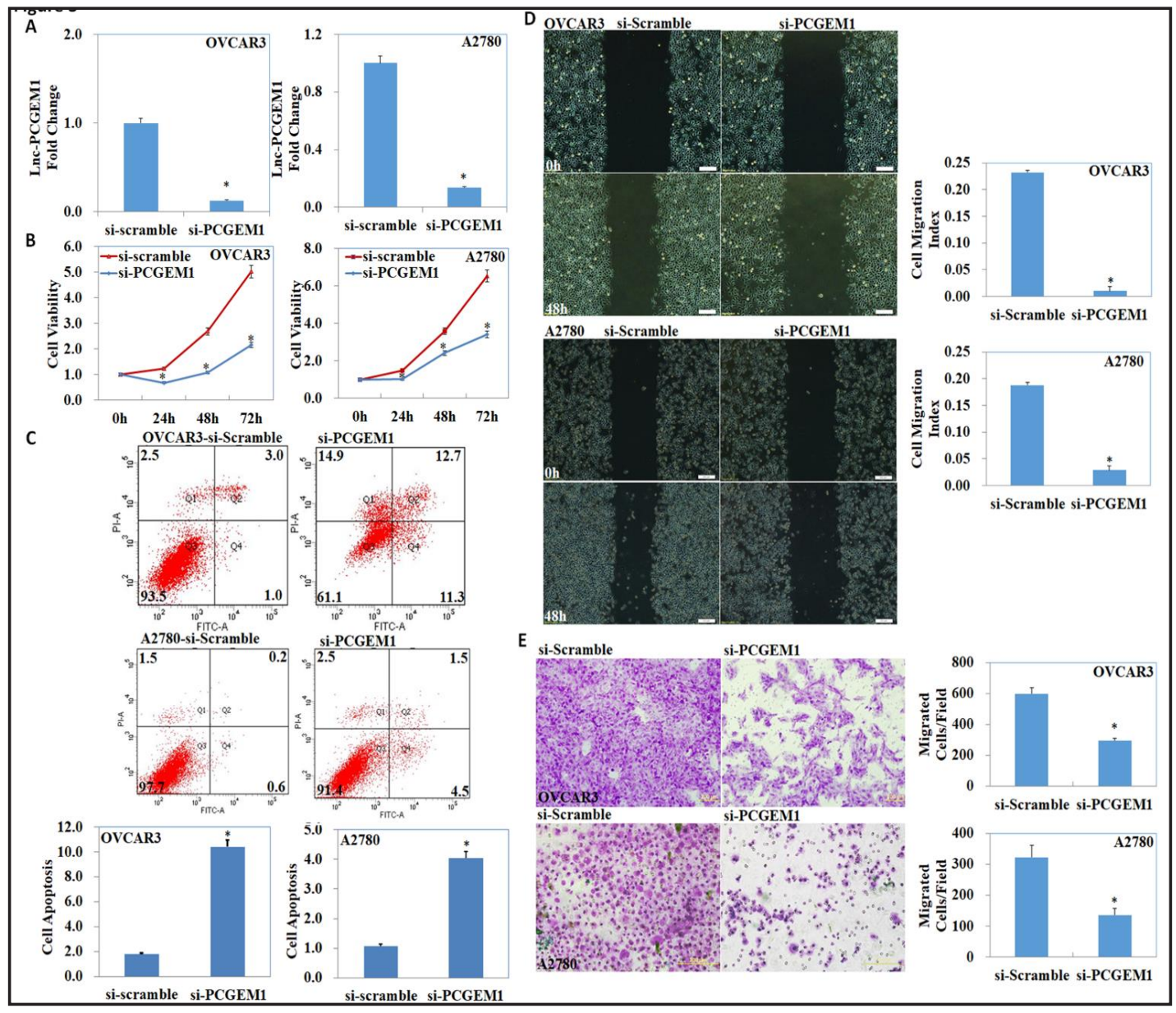

Fig. 3. Effect of PCGEM1 downregulation on ovarian cancer cell proliferation, apoptosis, and aggressiveness in vitro. (A) PCGEM1 downregulation (B) reduced cell proliferation, (C) increased apoptosis, and decreased (D) cell migration and (E) invasion ability. Results are representative of three separate experiments; data are the mean \pm SD. ${ }^{*} \mathrm{P}<0.05$. 


\section{Cellular Physiology Cell Physiol Biochem 2018:47:1578-1588 \begin{tabular}{l|l} 
DOI: 10.1159/000490931 & $\begin{array}{l}\text { O 2018 The Author(s). Published by S. Karger AG, Basel } \\
\text { www.karger.com/cpb }\end{array}$
\end{tabular}

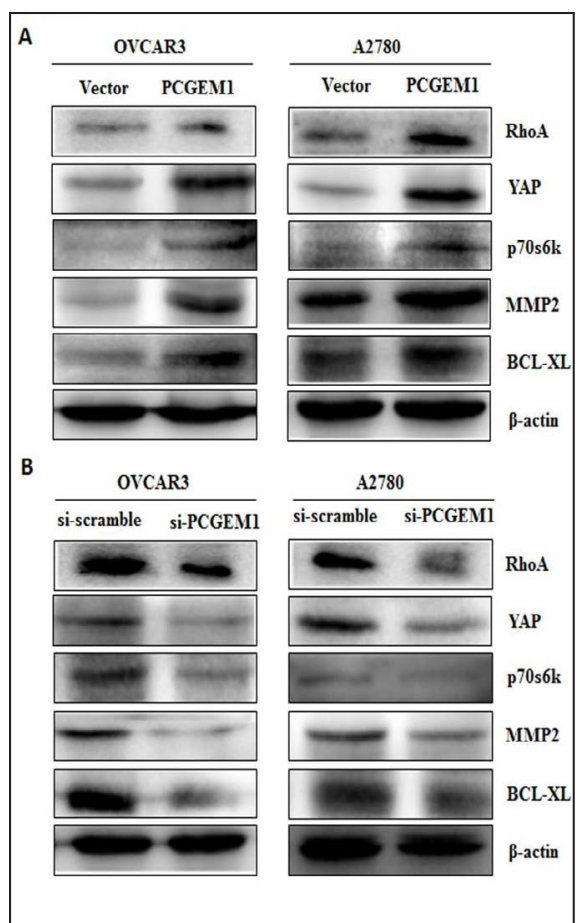

Fig. 4. Effect of PCGEM1 on ovarian carcinoma cell genotype in vitro. (A) PCGEM1 overexpression upregulated RhoA, YAP, P70S6K, MMP2, and BCL$\mathrm{xL}$ protein expression. (B) PCGEM1 downregulation downregulated RhoA, YAP, P70S6K, MMP2 and BCL-xL protein expression.

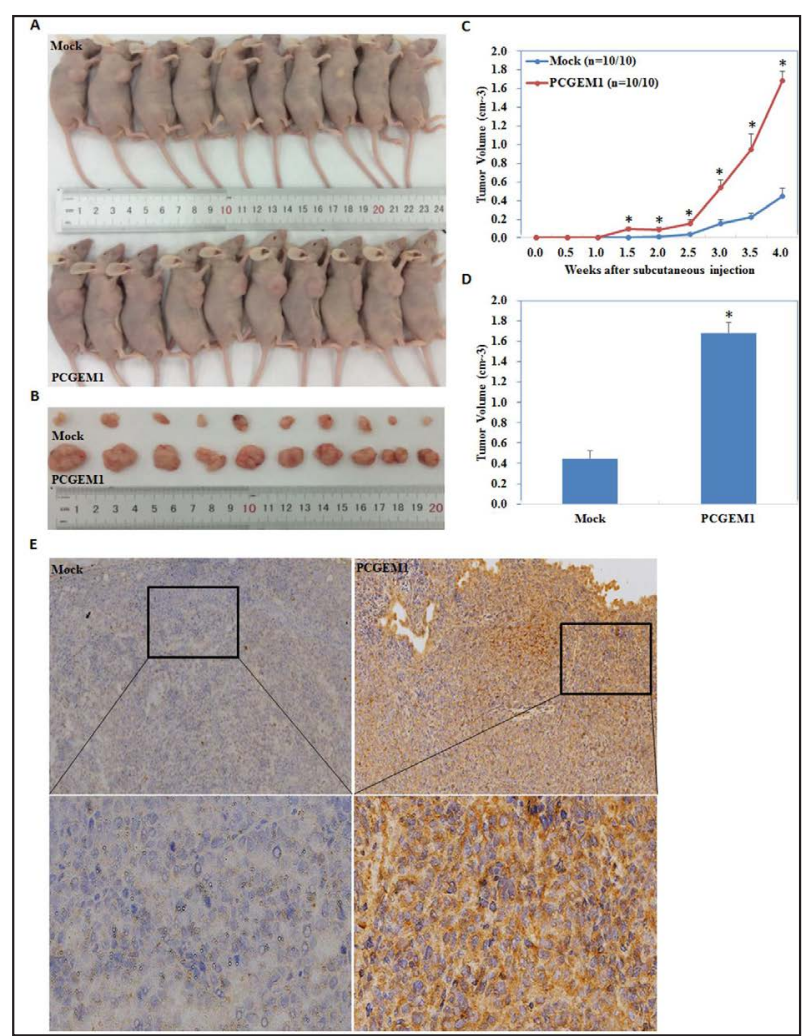

Fig. 5. Effect of PCGEM1 on tumor growth in vivo. (A-C) The tumor xenograft volume was greater in the PCGEM1 group compared to the mock group; (D) the tumor growth rate was also significantly greater in PCGEM1-transfected mice. (E) Immunohistochemical staining showing induced RhoA expression in the PCGEM1-transfected group.

that RhoA expression in the tumor tissues of the PCGEM1-transfected mice was significantly higher than that in the control (Fig. 5E).

\section{Effect of PCGEM1 on tumor progression via regulation of RhoA expression}

RHOA gene silencing in PCGEM1 overexpression ovarian cancer cells inhibited the proliferation-promoting effect of PCGEM1 (Fig. 6A, $P<0.05$ ), promoted apoptosis (Fig. 6B, $P<0.05$ ), and inhibited tumor metastasis (Fig. 6C, $P<0.05$ ) and invasion (Fig. 6D, $P<$ $0.05)$. The protein expression of RhoA and its downstream targets YAP, P70S6K, MMP2, and BCL-xL were also decreased as a result of the RHOA gene silencing (Fig. 6E), indicating that PCGEM1 may promote ovarian cancer tumorigenesis and progression by targeting RhoA and modulating the RhoA downstream factors YAP, P70S6K, MMP2, and Bcl/xL.

\section{Discussion}

Recently, lncRNAs, which are more than 200 nucleotides in length and with limited or no protein-coding capacity, have received increasing research attention [11]. Accumulating data strongly support the involvement of IncRNAs in cancer; IncRNA dysregulation has been considered as an underlying cause of human cancer and has been linked to cancer development and metastasis [12]. We focused on lncRNA PCGEM1, which is overexpressed in prostate cancer $[13,14]$ and glioma [4], and explored the relationship between PCGEM1 and the pathogenesis and progression of ovarian cancer. Our results showed that IncRNA 


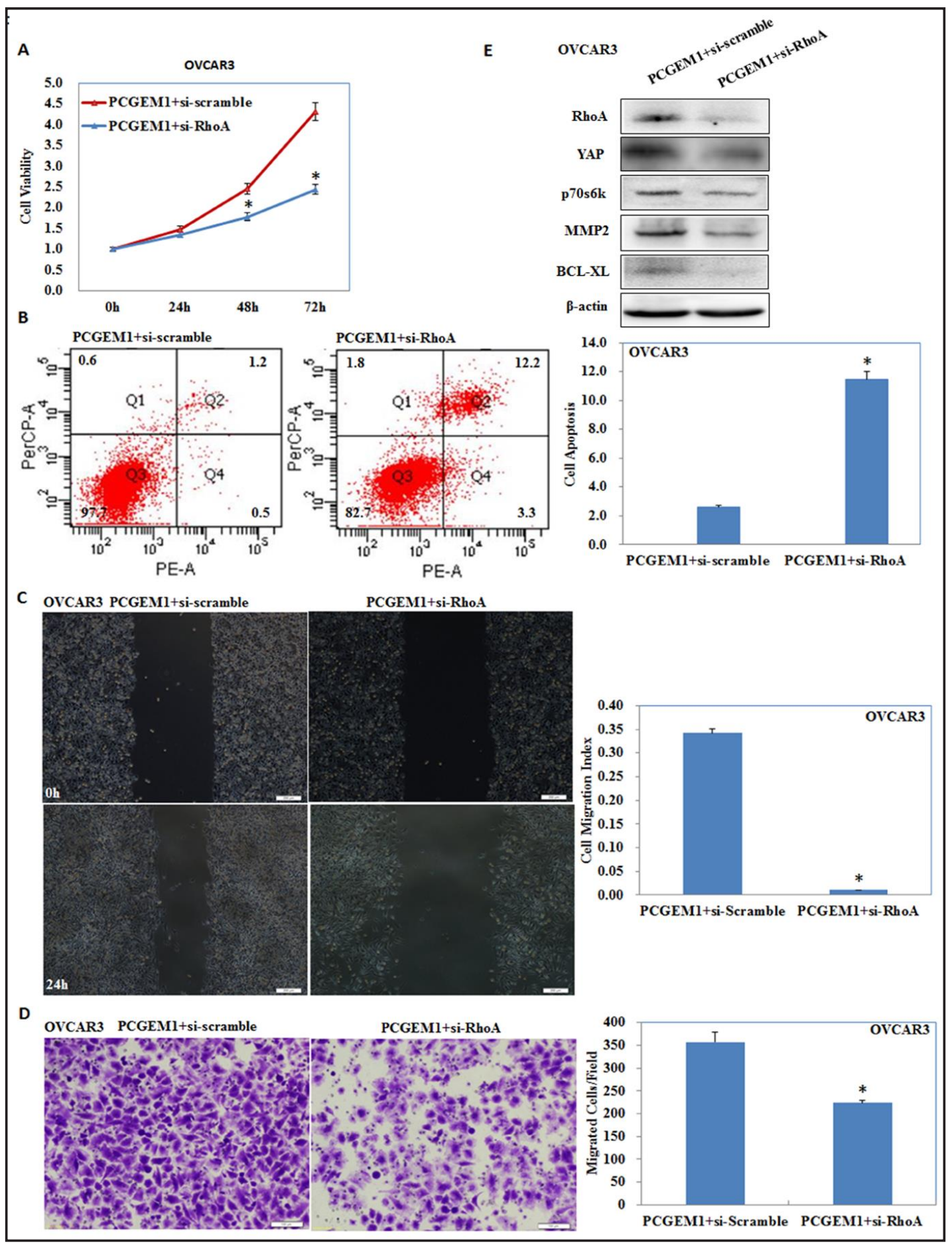

Fig. 6. RhoA downregulation reversed the effect of PCGEM1. RhoA downregulation (A) inhibited the cell proliferation-promoting effect of PCGEM1, (B) promoted apoptosis, and inhibited cancer cell (C) metastasis and (D) invasion. Downregulated (E) RhoA, YAP, P70S6K, MMP2, and BCL-xL expression. Results are representative of three separate experiments; data are the mean $\pm \mathrm{SD}$. ${ }^{*} \mathrm{P}<0.05$. 
PCGEM1 was significantly overexpressed in ovarian cancer tissues compared with normal ovarian tissue and was positively associated with differentiation, suggesting that PCGEM1 may also participate in ovarian cancer tumorigenesis.

We also found that PCGEM1 could induce ovarian cancer cell proliferation, migration, and invasion. Furthermore, PCGEM1 overexpression promoted tumor growth in vivo. Our results regarding the promoter role of PCGEM1 in the pathogenesis and progression of ovarian cancer are concordant with that of other researchers, who have reported that PCGEM1 overexpression inhibits apoptosis in LNCaP prostate cancer cells through modulating caspase 7 and PARP [14], stimulates osteoarthritic synoviocyte proliferation by acting as a sponge for miR-770 [5], and promote glioma development [4]. However, the mechanism of PCGEM1 in ovarian cancer is unknown.

Our results showed that PCGEM1 overexpression induced RhoA, YAP, P70S6K, Bcl-xL, and MMP2 expression, while PCGEM1 downregulation had the opposite effect. Previously, we showed that RHOA knockdown reduced ovarian cancer cell proliferation, promoted apoptosis, and suppressed lamellipodia formation and cell migration and invasion by downregulating the relevant genes, including that for P70S6K and Bcl-xL [6]. YAP is the major downstream cascade of Hippo signaling, designated the Hippo-YAP pathway, and has been identified as a candidate oncogene [15-19], Zhang et al. showed that RhoA knockdown mediated YAP downregulation, promoting apoptosis and inhibiting cell proliferation, cell cycle progression, and migration [20]. As reviewed by Hall [21], RhoA exerts multiple functions in tumor metastasis by orchestrating the action of multiple downstream effectors and promoting extracellular matrix degradation and reconstruction; Fagan-Solis et al. showed that blocking RhoA activity inhibited the invasive behavior of breast cancer cells by inhibiting MMP2 and MMP9 directly [22]. We found that RHOA gene silencing decreased the protein expression of RhoA and its downstream targets YAP, P70S6K, MMP2, and Bcl-xL. Combine with the bioinformatic prediction, we suggest that PCGEM1 may promote ovarian cancer tumorigenesis and progression by targeting RhoA and modulating the RhoA relative factors.

Our further experiments showed that silencing the RHOA gene in PCGEM1 overexpression ovarian cancer cells inhibited the tumor-promoting effect of PCGEM1, promoted apoptosis of the cancer cells, and inhibited tumor metastasis and invasion. Therefore, we believe that PCGEM1 may promote ovarian cancer tumorigenesis and progression by targeting RhoA and modulating the RhoA downstream factors YAP, P70S6K, MMP2, and Bcl/xL.

\section{Conclusion}

To conclude, we suggest that PCGEM1 acts as a promoter of ovarian epithelial cancer by targeting RhoA and modulating the abovementioned genes. Our investigation demonstrates the role of PCGEM1 in ovarian cancer tumorigenesis and development and is the first exploration of the underlying molecular mechanism.

\section{Abbreviations}

cDNA (complementary DNA); ceRNA (competing endogenous RNA); Ct (threshold cycle); FBS (fetal bovine serum); FIGO (International Federation of Gynecology and Obstetrics); lncRNA (long noncoding RNA); MMP2 (matrix metalloproteinase 2); MTT (tetrazolium); PBS (phosphate-buffered saline); PCGEM1 (prostate cancer gene expression marker 1); qRTPR (quantitative reverse transcription-PCR); siRNA (small interfering RNA); TBST (Trisbuffered saline containing Tween-20); YAP (Yes-associated protein). 


\section{Cellular Physiology Cell Physiol Biochem 2018;47:1578-1588 \begin{tabular}{l|l} 
and Biochemistry Published online: June 27, 2018 & $\begin{array}{l}\text { DOI: } 2018 \text { The Author(s). Published by S. Karger AG, Basel } \\
\text { www.karger.com/cpb }\end{array}$
\end{tabular}}

Chen et al.: The Role of PCGEM1 in Ovarian Carcinoma

\section{Acknowledgements}

The National Natural Science Foundation of China (Nos. 81772776; 81602266); and Science Foundation of China Medical University (No. XZR20160001). We would like to thank the native English speaking scientists of Elixigen Company (Huntington Beach, California) for editing our manuscript. YZ, SC conceived the study, wrote the manuscript and analyzed interpretation. SC, ZH Z, KX S, LL W, YL and XG carried out the experiments and analyzed the data. All authors read and approved the final manuscript.

\section{Disclosure Statement}

The authors state no conflict of interests.

\section{References}

1 Nezhat FR, Apostol R, Nezhat C, Pejovic T: New insights in the pathophysiology of ovarian cancer and implications for screening and prevention. Am J Obstet Gynecol 2015;213:262-267.

- Yeung TL, Leung CS, Yip KP, Au Yeung CL, Wong ST, Mok SC: Cellular and molecular processes in ovarian cancer metastasis. A Review in the Theme: Cell and Molecular Processes in Cancer Metastasis. Am J Physiol Cell Physiol 2015;309:C444-456.

-3 Hung CL, Wang LY, Yu YL, Chen HW, Srivastava S, Petrovics G, Kung HJ: A long noncoding RNA connects c-Myc to tumor metabolism. Proc Natl Acad Sci U S A 2014;111:18697-18702.

-4 Park JY, Lee JE, Park JB, Yoo H, Lee SH, Kim JH: Roles of Long Non-Coding RNAs on Tumorigenesis and Glioma Development. Brain Tumor Res Treat 2014;2:1-6.

5 Kang Y, Song J, Kim D, Ahn C, Park S, Chun CH, Jin EJ: PCGEM1 stimulates proliferation of osteoarthritic synoviocytes by acting as a sponge for miR-770. J Orthop Res 2016;34:412-418.

6 Chen S, Wang J, Gou WF, Xiu YL, Zheng HC, Zong ZH, Takano Y, Zhao Y: The involvement of RhoA and Wnt-5a in the tumorigenesis and progression of ovarian epithelial carcinoma. Int J Mol Sci 2013;14:24187-24199.

7 Jalali S, Bhartiya D, Lalwani MK, Sivasubbu S, Scaria V: Systematic Transcriptome Wide Analysis of IncRNAmiRNA Interactions. PLoS One 2013;8:e53823.

8 Ebert MS, Neilson JR, Sharp PA: MicroRNA sponges: competitive inhibitors of small RNAs in mammalian cells. Nat Methods 2007;4:721-726.

-9 Su Z, Zhi X, Zhang Q, Yang L, Xu H, Xu Z: LncRNA H19 functions as a competing endogenous RNA to regulate AQP3 expression by sponging miR-874 in the intestinal barrier. FEBS Lett 2016;590:1354-1364.

10 Liu XH, Sun M, Nie FQ, Ge YB, Zhang EB, Yin DD, Kong R, Xia R, Lu KH, Li JH, De W, Wang KM, Wang ZX: Lnc RNA HOTAIR functions as a competing endogenous RNA to regulate HER2 expression by sponging miR331-3p in gastric cancer. Mol Cancer 2014;13:92.

11 Chen T, Xie W, Xie L, Sun Y, Zhang Y, Shen Z, Sha N, Xu H, Wu Z, Hu H, Wu C: Expression of long noncoding RNA lncRNA-n336928 is correlated with tumor stage and grade and overall survival in bladder cancer. Biochem Biophys Res Commun 2015;468:666-670.

$\checkmark 12$ Gibb EA, Brown CJ, Lam WL: The functional role of long non-coding RNA in human carcinomas. Mol Cancer 2011;10:38.

13 Srikantan V, Zou Z, Petrovics G, Xu L, Augustus M, Davis L, Livezey JR, Connell T, Sesterhenn IA, Yoshino K, Buzard GS, Mostofi FK, McLeod DG, Moul JW, Srivastava S: PCGEM1, a prostate-specific gene, is overexpressed in prostate cancer. Proc Natl Acad Sci U S A 2000;97:12216-12221.

14 Fu X, Ravindranath L, Tran N, Petrovics G, Srivastava S: Regulation of apoptosis by a prostate-specific and prostate cancer-associated noncoding gene, PCGEM1. DNA Cell Biol 2006;25:135-141.

15 Tan G, Cao X, Dai Q, Zhang B, Huang J, Xiong S, Zhang Yy, Chen W, Yang J, Li H: A novel role for microRNA129-5p in inhibiting ovarian cancer cell proliferation and survival via direct suppression of transcriptional co-activators YAP and TAZ. Oncotarget 2015;6:8676-8686. 


\section{Cellular Physiology Cell Physiol Biochem 2018;47:1578-1588

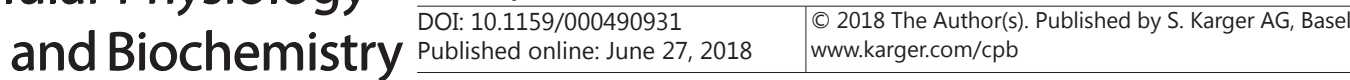 \\ Chen et al.: The Role of PCGEM1 in Ovarian Carcinoma}

16 Zhao B, Wei X, Li W, Udan RS, Yang Q Kim J, Xie J, Ikenoue T, Yu J, Li L, Zheng P, Ye K, Chinnaiyan A, Halder G, Lai ZC, Guan KL: Inactivation of YAP oncoprotein by the Hippo pathway is involved in cell contact inhibition and tissue growth control. Genes Dev 2007;21:2747-2761.

17 Zanconato F, Battilana G, Cordenonsi M, Piccolo S: YAP/TAZ as therapeutic targets in cancer. Curr Opin Pharmacol 2016;29:26-33.

18 Vici P, Ercolani C, Di Benedetto A, Pizzuti L, Di Lauro L, Sperati F, Terrenato I, Gamucci T, Natoli C, Di Filippo F, Botti C, Barba M, Mottolese M, De Maria R, Maugeri-Saccà M: Topographic expression of the Hippo transducers TAZ and YAP in triple-negative breast cancer treated with neoadjuvant chemotherapy. J Exp Clin Cancer Res 2016;35:62.

19 Beffagna G, Sacchetto R, Cavicchioli L, Sammarco A, Mainenti M, Ferro S, Trez D, Zulpo M, Michieletto $\mathrm{S}$, Cecchinato A, Goldschmidt M, Zappulli V: A preliminary investigation of the role of the transcription co-activators YAP/TAZ of the Hippo signalling pathway in canine and feline mammary tumours. Vet J 2016;207:105-111.

20 Zhang Y, Xia H, Ge X, Chen Q, Yuan D, Chen Q Leng W, Chen L, Tang Q, Bi F: CD44 acts through RhoA to regulate YAP signaling. Cell Signal 2014;26:2504-2513.

-21 Hall A: Rho GTPases and the actin cytoskeleton. Science 1998;279:509-514.

22 Fagan-Solis KD, Schneider SS, Pentecost BT, Bentley BA, Otis CN, Gierthy JF, Arcaro KF: The RhoA Pathway Mediates MMP-2 and MMP-9-Independent Invasive Behavior in a Triple-Negative Breast Cancer Cell Line. J Cell Biochem 2013;114:1385-1394. 